\title{
A retrospective single-center study comparing clinical outcomes of 3-dimensional and 2-dimensional laparoscopic cholecystectomy in acute cholecystitis
}

\author{
Jong-Jin Yun, Eun-young Kim, Eun-Jung Ahn, Jeong-Ki Kim, Ji-Hye Choi, \\ Jong-Min Park, and Sei Hyeog Park
}

\author{
Department of Surgery, National Medical Center, Seoul, Korea
}

\begin{abstract}
Backgrounds/Aims: Laparoscopic cholecystectomy (LC) has become widely used and preferred standard treatment for gallbladder (GB) disease in many countries. In this study, we aimed to compare the overall clinical outcomes of 3-dimensional (3D) LC system with those of the 2D LC method. Methods: We retrospectively analyzed patients who underwent LC for acute cholecystitis between January 2010 and March 2019 at the National Medical Center in Korea. We entered them into 3D LC (group A) and 2D LC (group B) groups. We used Olympus CLV-190 laparoscopic device with dual lenses, capable of displaying both $3 D$ and $2 D$ images. Postoperative variables considered for evaluating between-group differences in clinical outcomes included diet resumption period after surgery, postoperative hospital length-of-stay, outpatient department follow-up period, surgical time, and postoperative surgery-related complications (blood loss and open conversion). Results: We analyzed 278 acute cholecystitis patients (Group A, n=116; Group B, $n=162$ ). Compared to group $B$, group A had a significantly reduced surgical time and postoperative hospital stay. Although underlying diseases and abdominal surgical history were more prevalent in the 3D LC group, no significant between-group differences in blood loss and open conversion rate were observed. Conclusions: The 3D imaging system offered many advantages over 2D LC, including reduced surgical time and shorter postoperative hospital stay; therefore, it has significance in reducing hospital costs. (Ann Hepatobiliary Pancreat Surg 2019;23:339-343)
\end{abstract}

Key Words: 3D laparoscopic cholecystectomy; 2D laparoscopic cholecystectomy; Acute cholecystitis; Gallbladder

\section{INTRODUCTION}

Laparoscopic cholecystectomy (LC) has become a widely used treatment for gallbladder (GB) disease. It is also the most preferred standard option of cholecystectomy in many countries. ${ }^{1}$

Various studies showed a significant reduction in operation time of LC when using 3-dimensional (3D) imaging systems, compared to the $2 \mathrm{D}$ procedure. ${ }^{2-6}$ However, studies showing no significant difference between these 2 systems used older versions of $3 \mathrm{D}$ instruments. ${ }^{7-10}$ Only a few comparative studies have been conducted with the new 3D imaging systems (Viking, da Vinci), which suggested the $3 \mathrm{D}$ system to be superior to the $2 \mathrm{D}$ system. ${ }^{2,5,6}$

In this study, we reviewed our surgical experience in the management of acute cholecystitis (AC) retrospectively. We aimed to compare the clinical outcomes of $3 \mathrm{D}$ and 2D LC systems.

\section{MATERIALS AND METHODS}

\section{Study design}

This study was approved by the Institutional Review Board of National Medical Center, Korea. We retrospectively enrolled patients who underwent LC for AC between January 2010 and March 2019 at the National Medical Center in Korea. We divided the patients into two groups, based on the laparoscopic system used (Group A, 3D LC; Group B, 2D LC).

Patients were diagnosed with AC based on Tokyo

Received: September 16, 2019; Revised: September 16, 2019; Accepted: September 17, 2019 Corresponding author: Sei Hyeog Park

Department of Surgery, National Medical Center, 245 Eulji-ro, Jung-gu, Seoul 04564, Korea Tel: +82-2-2260-7092, Fax: +82-2-2260-7142, E-mail: spark479@unitel.co.kr

Copyright (C) 2019 by The Korean Association of Hepato-Biliary-Pancreatic Surgery

This is an Open Access article distributed under the terms of the Creative Commons Attribution Non-Commercial License (http://creativecommons.org/ censes/by-nc/4.0) which permits unrestricted non-commercial use, distribution, and reproduction in any medium, provided the original work is properly cited. Annals of Hepato-Biliary-Pancreatic Surgery • pISSN: 2508-5778 - eISSN: 2508-5859 
Guidelines, ${ }^{11,12}$ using computed tomography of the abdomen and abdominopelvic cavity. Computed tomography findings for AC included gallstone, GB empyema, and gangrenous cholecystitis. We excluded participants diagnosed with GB cancer, GB polyps, and adenomyomatosis.

\section{Variables}

LC method (3D LC and 2D LC) was the major independent variable. We evaluated the baseline characteristics, including age, sex, American Society of Anesthesiologists (ASA) score, albumin level, body mass index (BMI), percutaneous transhepatic gallbladder drainage (PTGBD) insertion, White blood cell (WBC) count, total bilirubin, aspartate aminotransferase, and alanine aminotransferase levels.

Surgical history, as a preoperative variable, was evaluated and categorized into abdominal (appendectomy, C-section, hysterectomy, abdominal cancer surgery, and primary stomach repair) and non-abdominal surgical (thyroidectomy, hemorrhoidectomy, and orthopedic surgery) groups. We also investigated the effect of history of abdominal surgery on operation time and open conversion rate due to adhesions.

We evaluated other preoperative factors, including diabetes mellitus, hypertension, and comorbidities, (medical history of cardiovascular disease, chronic kidney disease requiring hemodialysis, chronic obstructive pulmonary disease, cerebrovascular disease, and liver cirrhosis), which were considered due to the risk of a surgical com- plication, including blood loss.

Furthermore, we recorded postoperative variables, including diet resumption period after surgery, outpatient department follow-up period, postoperative hospital length-of-stay, surgical time, and postoperative surgery-related complications (blood loss and open conversion), which were considered for between-group differences in clinical outcomes. These covariants were obtained by chart review.

\section{Treatment methods}

Preoperative examinations in all patients included blood chemistry profiling, electrocardiogram, and plain chest radiography. 2D-echocardiography was performed in diabetic and hypertensive ( $>5$ years) patients, and those aged $>65$ years. Pulmonary function test was carried out in patients aged $>65$ years and with a history of pulmonary complications. We consulted a physician about the preoperative management of patients with cardiovascular, chronic kidney (requiring hemodialysis), cerebrovascular, and pulmonary diseases.

All surgeries were performed with the conventional 4-hole LC method using Olympus CLV-190 laparoscopic device with dual lenses, capable of displaying both 3D and 2D images. However, conversion to open cholecystectomy was needed in cases of severe adhesion, uncontrolled bleeding, common bile duct injury, and Mirizzi syndrome. PTGBD was performed under local anesthesia using ultrasonography by an interventional radiologist.

Table 1. Preoperative patient characteristics

\begin{tabular}{lccr}
\hline \multicolumn{1}{c}{ Characteristics } & 3D (Group A) $(\mathrm{n}=116)$ & 2D (Group B) (n=162) & $p$-value \\
\hline Age (year)* & $63.97 \pm 13.58$ & $61.62 \pm 13.38$ & 0.123 \\
Gender (male) & $61(52.6)$ & $100(61.7)$ & 0.128 \\
Gender (female) & $55(47.4)$ & $162(38.3)$ & 0.278 \\
ASA score* & $1.93 \pm 0.46$ & $2.02 \pm 0.67$ & 0.052 \\
Albumin $(\mathrm{g} / \mathrm{dl})^{*}$ & $3.73 \pm 0.69$ & $3.58 \pm 0.61$ & 0.979 \\
BMI $\left(\mathrm{kg} / \mathrm{m}^{2}\right)^{*}$ & $24.63 \pm 3.79$ & $24.53 \pm 4.04$ & 0.027 \\
PTGBD & $51(44.0)$ & $93(57.4)$ & $<0.001$ \\
WBC count* & $10187.07 \pm 4634.25$ & $12151.85 \pm 3991.35$ & $<0.001$ \\
Total bilirubin $(\mathrm{mg} / \mathrm{dl})^{*}$ & $1.17 \pm 1.22$ & $1.69 \pm 1.59$ & 0.947 \\
AST $(\mathrm{U} / \mathrm{L})^{*}$ & $106.34 \pm 182.29$ & $72.34 \pm 127.72$ & 0.940 \\
ALT $(\mathrm{U} / \mathrm{L})^{*}$ & $77.53 \pm 128.92$ & $61.60 \pm 104.90$ & \\
\hline
\end{tabular}

Values are numbers (percentages) unless otherwise stated

ASA, American Society of Anesthesiologists; BMI, Body Mass Index; PTGBD, Percutaneous Transhepatic Gallbladder Drainage; WBC, White Blood Cell; AST, Aspartate aminotransferase; ALT, Alanine aminotransferase

*Values are mean 
PTGBD was actively performed in patients with distended GB, leukocytosis, and fever as a bridging treatment. After stabilization of hemodynamic state and correction of comorbidities, each patient underwent laparoscopic surgery promptly on scheduled time.

\section{Statistical analyses}

All statistical analyses were performed using the SPSS software program version 18.0 (SPSS Inc., Chicago, Illinois, USA). The chi-square test was performed for the analysis of categorical variables and ANOVA for continuous variables. A $p$-value $<0.05$ was considered statistically significant.

\section{RESULTS}

We assessed 278 patients who underwent LC for AC during the study period. There were 116 and 162 patients in the $3 \mathrm{D}$ (group A) and 2D LC system (group B) groups, respectively, and between-group differences in clinical characteristics were compared.

Table 1 shows the preoperative characteristics of the participants. No significantly differences in patients' age

Table 2. Surgical history according to $3 \mathrm{D}$ LC vs. $2 \mathrm{D}$ LC

\begin{tabular}{lcrl}
\hline Surgical history & $3 \mathrm{D}(\mathrm{n}=116)$ & $2 \mathrm{D}(\mathrm{n}=162)$ & $p$-value \\
\hline No & $67(57.8)$ & $127(78.4)$ & \\
Yes & $49(42.2)$ & $35(21.6)$ & $<0.001$ \\
Abdominal* & $21(18.1)$ & $24(14.8)$ & \\
Non-abdominal** $^{*}$ & $28(24.1)$ & $11(6.8)$ & \\
\hline
\end{tabular}

Values are numbers (percentages) unless otherwise stated *Abdominal: appendectomy, C-section, hysterectomy, abdominal cancer surgery, and primary stomach repair

**Non-abdominal: thyroidectomy, hemorrhoidectomy, and orthopedic surgery or sex, physical status (based on ASA score), body mass index, aspartate aminotransferase, and alanine aminotransferase levels were observed between the groups. Albumin level showed a slightly increasing trend in group A than in group B. Compared to group A, WBC counts and serum total bilirubin levels were significantly higher in group B. Moreover, preoperative PTGBD was performed more frequently in 2D LC group.

Table 2 shows the surgical history in each group. There were significant between-group differences in patient's surgical history with group A exhibiting a higher percentage of abdominal (18.1\% vs. $14.8 \%)$ and non-abdominal $(24.1 \%$ vs. $6.8 \%)$ surgeries than in the group B.

Significant between-group differences were observed in underlying diseases (Table 3) with a higher prevalence of diabetes and hypertension in group $\mathrm{B}$, whereas serious comorbidities (except chronic obstructive pulmonary disease) were more prevalent in group A.

Table 3. Underlying diseases according to $3 \mathrm{D} L C$ vs. $2 \mathrm{D} L C$

\begin{tabular}{lcccc}
\hline \multicolumn{1}{c}{ Underlying diseases } & $3 \mathrm{D}(\mathrm{n}=116)$ & $2 \mathrm{D}(\mathrm{n}=162)$ & $p$-value \\
\hline No & $23(19.8)$ & $53(32.7)$ & \\
Yes & $93(80.2)$ & $109(67.3)$ & 0.017 \\
$\begin{array}{l}\text { Diabetes mellitus, } \\
\text { hypertension }\end{array}$ & $53(45.7)$ & $77(47.5)$ & \\
$\begin{array}{l}\text { Serious comorbidities* } \\
\text { Cardiovascular }\end{array}$ & $31(26.7)$ & $39(24.0)$ & \\
$\begin{array}{l}\text { Chronic kidney disease } \\
\quad \text { requiring hemodialysis }\end{array}$ & $3(6.0)$ & $9(5.6)$ & \\
$\quad \begin{array}{l}\text { Chronic obstructive } \\
\text { pulmonary disease }\end{array}$ & $3(2.6)$ & $8(2.5)$ & \\
$\quad \begin{array}{l}\text { Cerebrovascular } \\
\text { Liver cirrhosis }\end{array}$ & $13(11.2)$ & $15(9.9)$ \\
\hline
\end{tabular}

Values are numbers (percentages) unless otherwise stated * Serious comorbidities: cardiovascular disease, chronic kidney disease requiring hemodialysis, chronic obstructive pulmonary disease, cerebrovascular disease, liver cirrhosis

Table 4. Surgical outcomes according to $3 \mathrm{D}$ LC vs. 2D LC

\begin{tabular}{lccr}
\hline \multicolumn{1}{c}{ Surgical outcomes } & 3D $(\mathrm{n}=116)$ & 2D $(\mathrm{n}=162)$ & $p$-value \\
\hline Diet start (day)* & $2.43 \pm 1.14$ & $2.25 \pm 1.34$ & 0.051 \\
Postoperative stay (day)* & $5.71 \pm 4.75$ & $6.99 \pm 6.79$ & 0.205 \\
outpatient department follow-up period (day)* & $8.62 \pm 12.97$ & $48.92 \pm 121.73$ & $<0.001$ \\
Surgical time (min)* & $54.88 \pm 28.68$ & $86.31 \pm 35.07$ & $<0.001$ \\
Blood loss (cc)* & $28.96 \pm 79.41$ & $29.99 \pm 45.75$ & $<0.001$ \\
Open conversion & $10(8.6)$ & $15(9.3)$ & 0.854 \\
\hline
\end{tabular}

Values are numbers (percentages) unless otherwise stated

*Values are mean 
Table 4 shows a comparison of postoperative clinical results. Diet resumption period after surgery (-2-day) was comparable in both the groups. Group B showed significantly delayed outpatient department follow-up period and longer hospital length-of-stay than in the group A. Compared to group B, surgical time was significantly reduced in the group A. There was no significant difference in mean blood loss (mean \pm standard deviation, Group A, $28.96 \pm 79.41$; Group B, 29.99 \pm 45.75 ), and open conversion rate between the two groups.

\section{DISCUSSION}

GB stone diseases are common in the developed countries $^{13-16}$ with approximately 500,000 cholecystectomies performed every year in the United States, ${ }^{17}$ constituting a major economic burden of the disease. Currently, LC is the most preferred and cost-effective standard treatment option in gallstone disease, ${ }^{1}$ which reduces the operation time without compromising safety. LC procedure involves $3 \mathrm{D}$ and $2 \mathrm{D}$ imaging systems.

In this study, we sought to evaluate clinical outcomes of 3D LC system in comparison with 2D LC method. We showed that the 3D laparoscopic system significantly reduced the surgical time and postoperative hospital stay, compared to $2 \mathrm{D}$ LC procedure.

There is only 1 systematic review assessing the benefits and limitations of the use of 3D systems versus 2D systems for LC in the literature. ${ }^{18}$ The only prospective randomized comparative study in this review was belonged to Hanna et al. ${ }^{8}$ who reported that $3 \mathrm{D}$ imaging was not superior in comparison with 2D imaging when considering the operation execution time. However, on contrary to ours, they had used a first-generation single-lens laparoscope, which does not project a true stereoscopic vision to the operator. ${ }^{3}$ Stereopsis is the "binocular perception" of relative distance, or the depth separation, between objects that occurs as a result of neural processing of the relative horizontal disparities between the monocular retinal images. Binocular disparities are present because the lateral separation of the eyes in the head provides each eye with a slightly disparate view of a given object. ${ }^{19}$ The differences in position between left and right retinal images, termed binocular disparities, can be used by the visual system to recover $3 \mathrm{D}$ information from $2 \mathrm{D}$ images.
Indeed, stereopsis is important, especially for tasks requiring fine manipulative skills and spatial discriminations, such as threading a needle or surgeries with minimal access like laparoscopic surgeries. ${ }^{20,21}$ Stereopsis and depth perception are not synonymous. Monocular clues including object overlap, relative object size, highlights and shadows, motion parallax, and perspective contribute to depth perception. ${ }^{22}$ However, stereopsis is the highest form of binocular cooperation, and it adds a new quality to vision ${ }^{22}$ that is accomplished by bichannel optical systems rather than single-channel optic systems. We used a dual-lens laparoscope in our studies. Previous studies showed that when contrast was the same in the 2 eyes, binocular acuity was better than best monocular acuity by an average of $0.045 \mathrm{log}$ minimum angle of resolution, or $11 \%,{ }^{23,24}$ which means that normal binocular vision improves functional vision by binocular summation and stereopsis. ${ }^{19}$ Therefore, using the bichannel optical system, the surgeon has a heightened spatial perception and can work faster and more safely than with a single-channel system. ${ }^{25}$ Moreover another study comparing the 3D and 2D system by using dual lenses evaluated only the operation time of $\mathrm{LC}^{26}$ Effect of the $3 \mathrm{D}$ system on the performance of the surgeon and its utility as and educational tool for laparoscopic surgery has also been highlighted in the literature. ${ }^{2,5,6,10}$

This study had several limitations. Firstly, only one surgeon familiar with the $3 \mathrm{D}$ system performed all the LC procedure; however, the assistants kept changing. Therefore, the outcome of the surgery may vary depending on the experience of the assistants. Secondly, although we expected lesser surgical complications in 3D LC, which provides a better operation field than $2 \mathrm{D}$, blood loss and open conversion rate were comparable in both the groups. Patient's underlying diseases could lead to more blood loss during surgery, with adhesion by abdominal surgical history causing more open conversion rate. However, correlations of underlying disease and adhesion due to surgical history with postoperative surgical complications (open conversion rate and blood loss) were not included in this study; therefore, it needs to be explored in future investigations.

In conclusion, the 3D laparoscopic system, which allows $3 \mathrm{D}$ accesses, provides better perspective than the $2 \mathrm{D}$ system. It also gives a better recognizable structural view 
around the GB and Calot's triangle. The 3D imaging system showed many advantages over $2 \mathrm{D}$ LC, including reduced surgical time and shorter postoperative hospital stay. A shorter surgical time reduces the exposure time to anesthesia. Therefore, it has a significant impact on patient safety. Besides, shorter duration of postoperative hospital stay reduces the hospital costs, enabling an early return to physical activity and work.

\section{REFERENCES}

1. Keus F, Gooszen HG, van Laarhoven CJ. Open, small-incision, or laparoscopic cholecystectomy for patients with symptomatic cholecystolithiasis. An overview of Cochrane Hepato-Biliary Group reviews. Cochrane Database Syst Rev 2010;(1):CD008318.

2. Byrn JC, Schluender S, Divino CM, Conrad J, Gurland B, Shlasko E, et al. Three-dimensional imaging improves surgical performance for both novice and experienced operators using the da Vinci Robot System. Am J Surg 2007;193:519-522.

3. Jourdan IC, Dutson E, Garcia A, Vleugels T, Leroy J, Mutter $\mathrm{D}$, et al. Stereoscopic vision provides a significant advantage for precision robotic laparoscopy. Br J Surg 2004;91:879-885.

4. van Bergen P, Kunert W, Bessell J, Buess GF. Comparative study of two-dimensional and three-dimensional vision systems for minimally invasive surgery. Surg Endosc 1998;12:948-954.

5. Yohannes P, Rotariu P, Pinto P, Smith AD, Lee BR. Comparison of robotic versus laparoscopic skills: is there a difference in the learning curve? Urology 2002;60:39-45; discussion 45.

6. Votanopoulos K, Brunicardi FC, Thornby J, Bellows CF. Impact of three-dimensional vision in laparoscopic training. World $\mathrm{J}$ Surg 2008;32:110-118.

7. Falk V, Mintz D, Grünenfelder J, Fann JI, Burdon TA. Influence of three-dimensional vision on surgical telemanipulator performance. Surg Endosc 2001;15:1282-1288.

8. Hanna GB, Shimi SM, Cuschieri A. Randomised study of influence of two-dimensional versus three-dimensional imaging on performance of laparoscopic cholecystectomy. Lancet 1998;351: 248-251.

9. Herron DM, Lantis JC 2nd, Maykel J, Basu C, Schwaitzberg SD. The 3-D monitor and head-mounted display. Surg Endosc 1999; 13:751-755.

10. Chan AC, Chung SC, Yim AP, Lau JY, Ng EK, Li AK. Comparison of two-dimensional vs three-dimensional camera systems in laparoscopic surgery. Surg Endosc 1997;11:438-440.

11. Tokyo Guidelines for the management of acute cholangitis and cholecystitis. proceedings of a consensus meeting, April 2006, Tokyo, Japan. J Hepatobiliary Pancreat Surg 2007;14:1-121.

12. Yokoe M, Takada T, Strasberg SM, Solomkin JS, Mayumi T, Gomi H, et al.; Tokyo Guidelines Revision Committee. New diagnostic criteria and severity assessment of acute cholecystitis in revised Tokyo Guidelines. J Hepatobiliary Pancreat Sci 2012; 19:578-585

13. Halldestam I, Enell EL, Kullman E, Borch K. Development of symptoms and complications in individuals with asymptomatic gallstones. Br J Surg 2004;91:734-738.

14. Janzon L, Aspelin P, Eriksson S, Hildell J, Trell E, Ostberg H. Ultrasonographic screening for gallstone disease in middle-aged women. detection rate, symptoms, and biochemical features. Scand J Gastroenterol 1985;20:706-710.

15. Prevalence of gallstone disease in an Italian adult female population. Rome Group for the Epidemiology and Prevention of Cholelithiasis (GREPCO). Am J Epidemiol 1984;119:796805.

16. Jørgensen T. Abdominal symptoms and gallstone disease: an epidemiological investigation. Hepatol 1989;9:856-860.

17. Schirmer BD, Winters KL, Edlich RF. Cholelithiasis and cholecystitis. J Long Term Eff Med Implants 2005;15:329-338.

18. Gurusamy KS, Sahay S, Davidson BR. Three dimensional versus two dimensional imaging for laparoscopic cholecystectomy. Cochrane Database Syst Rev 2011;(1):CD006882.

19. Harweth RS, Schor CM. Binocular vision. In: Kaufman PL, Alm A, eds. Adler's physiology of the eye.2. St. Louis: The CVMosby Co, 2003:484-510.

20. Munz Y, Moorthy K, Dosis A, Hernandez JD, Bann S, Bello $\mathrm{F}$, et al. The benefits of stereoscopic vision in robotic-assisted performance on bench models. Surg Endosc 2004;18:611-616.

21. Yamauchi Y, Shinohara K. Effect of binocular stereopsis on surgical manipulation performance and fatigue when using a stereoscopic endoscope. Stud Health Technol Inform 2005;111:611614.

22. Raab EL. 2011--2012 sensory physiology and pathology. basicand clinical science course, section 6: pediatric ophthalomology and strabismus. Fort Rucker: Aircrew health and performance division, US army aeromedical research laboratory, 2011:39-59.

23. Cagenello R, Arditi A, Halpern DL. Binocular enhancement of visual acuity. J Opt Soc Am A Opt Image Sci Vis 1993;10:18411848.

24. Rabin J. Two eyes are better than one: binocular enhancement in the contrast domain. Ophthalmic Physiol Opt 1995;15:45-48.

25. van Bergen $P$, Kunert W, Buess GF. Three-dimensional (3-D) video systems: bi-channel or single-channel optics? Endoscopy 1999;31:732-737.

26. Bilgen K, Ustün M, Karakahya M, Işik S, Sengül S, Cetinkünar $\mathrm{S}$, et al. Comparison of $3 \mathrm{D}$ imaging and 2D imaging for performance time of laparoscopic cholecystectomy. Surg Laparosc Endosc Percutan Tech 2013;23:180-183. 